
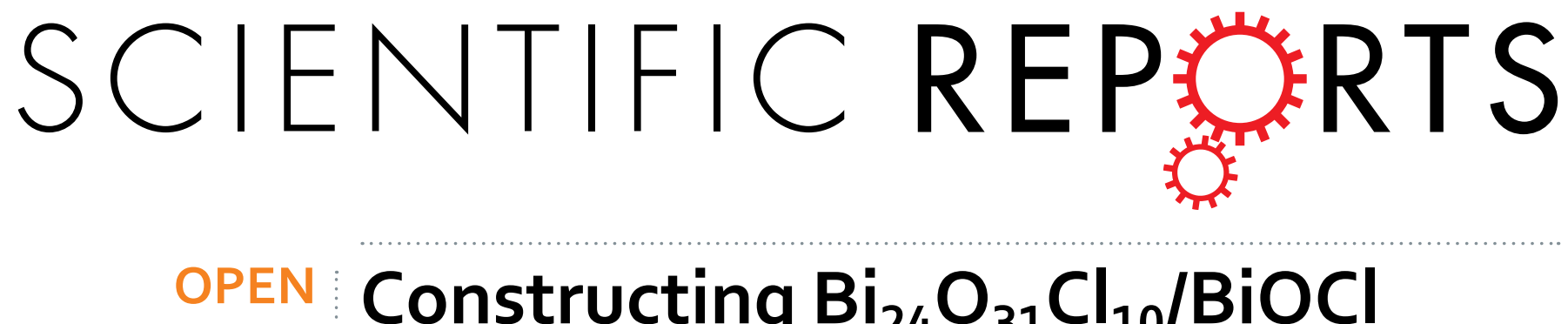

\title{
Constructing $\mathrm{Bi}_{24} \mathrm{O}_{31} \mathrm{Cl}_{10} / \mathrm{BiOCl}$
} heterojunction via a simple thermal annealing route for achieving

Received: 18 February 2016

Accepted: 08 June 2016

Published: 24 June 2016 \section{enhanced photocatalytic activity and selectivity}

\author{
Xiaoyan Liu, Yiguo Su, Qihang Zhao, Chunfang Du* \& Zhiliang Liu*
}

This work reports on the construction of a $\mathrm{Bi}_{24} \mathrm{O}_{31} \mathrm{Cl}_{10} / \mathrm{BiOCl}$ heterojunction via a simple thermal annealing method. The X-ray diffraction (XRD) results indicated that the phase transformation from $\mathrm{BiOCl}$ to $\mathrm{Bi}_{24} \mathrm{O}_{31} \mathrm{Cl}_{10}$ could be realized during the thermal annealing process. The high-resolution transmission electron microscopy (HRTEM) images, $X$-ray photoelectron spectroscopy (XPS) binding energy shifts, Raman spectra and Fouier transform infrared spectroscopy (FT-IR) spectra confirmed the formation of the $\mathrm{Bi}_{24} \mathrm{O}_{31} \mathrm{Cl}_{10} / \mathrm{BiOCl}$ heterojunction. The obtained $\mathrm{Bi}_{24} \mathrm{O}_{31} \mathrm{Cl}_{10} / \mathrm{BiOCl}$ photocatalyst showed excellent conversion efficiency and selectivity toward photocatalytic conversion of benzyl alcohol to benzaldehyde under visible light irradiation. The radical scavengers and electron spin resonance (ESR) results suggested that the photogenerated holes were the dominant reactive species responsible for the photocatalytic oxidation of benzyl alcohol and superoxide radicals were not involved in the photocatalytic process. The in-situ generation of $\mathrm{Bi}_{24} \mathrm{O}_{31} \mathrm{Cl}_{10} / \mathrm{BiOCl}$ heterojunction may own superior interfacial contact than the two-step synthesized heterojunctions, which promotes the transfer of photogenerated charge carriers and is favorable for excellent photocatalytic activities.

Regarding the future environmental and energy concerns, the development of green and sustainable chemical conversions has attracted enormous interest ${ }^{1-3}$. Alcohol oxidations are one of the most frequently investigated reactions because of their industrial essentiality in the commercial synthesis of multifarious materials, such as plastics, perfumes, paints, etc ${ }^{4-6}$. Compared with conventional methods, photocatalytic technology is considered to be a green, reliable and economic method for the oxidation of alcohols into the corresponding aldehydes due to the massive solar energy and $\mathrm{O}_{2}{ }^{7-11}$.

Semiconductor titanium dioxide $\left(\mathrm{TiO}_{2}\right)$ is universally regarded as an efficient photocatalyst toward decomposition of various organic pollutants ${ }^{12-17}$. Moreover, it also displays photocatalytic activity toward the oxidation of benzyl alcohol to benzaldehyde under UV-light and visible-light irradiation, which shows high conversion efficiency $(>99 \%)$ and selectivity $(>99 \%)^{18,19}$. Recently, considerable attention has been devoted to another series of semiconductors, the bismuth-based semiconductors. $\mathrm{BiOCl}$ is a V-VI-VII ternary semiconductor, consisting of internal structure of $\left[\mathrm{Bi}_{2} \mathrm{O}_{2}\right]^{2+}$ layers sandwiched by two slabs of $\mathrm{Cl}$ atoms which induces the growth of $\mathrm{BiOCl}$ along a particular axis ${ }^{20}$. It often shows high photocatalytic performance than $\mathrm{TiO}_{2}(\mathrm{P} 25$, Degussa) under UV-light irradiation due to its unique layered atomic structure, which favors the transfer and separation of photogenerated charge carriers and subsequently enhances the photocatalytic activity ${ }^{21,22}$. However, $\mathrm{BiOCl}$ is a wide-band-gap $(3.17 \sim 3.54 \mathrm{eV})$ semiconductor ${ }^{23,24}$, which leads to a poor photocatalytic performance under visible light irradiation.

Constructing heterojunction composed of $\mathrm{BiOCl}$ and another narrow band-gap semiconductor with suitable conduction band $(\mathrm{CB})$ and valence band $(\mathrm{VB})$ can efficiently improve the visible-light harvesting and inhibit the electron-hole recombination as well as raise the lifetime of charge carriers. A variety of heterojunction systems

College of Chemistry and Chemical Engineering, Inner Mongolia University, Hohhot, Inner Mongolia 010021, P. R. China. "These authors contributed equally to this work. Correspondence and requests for materials should be addressed to C.D. (email: cedchf@imu.edu.cn) or Z.L. (email: cezlliu@imu.edu.cn) 

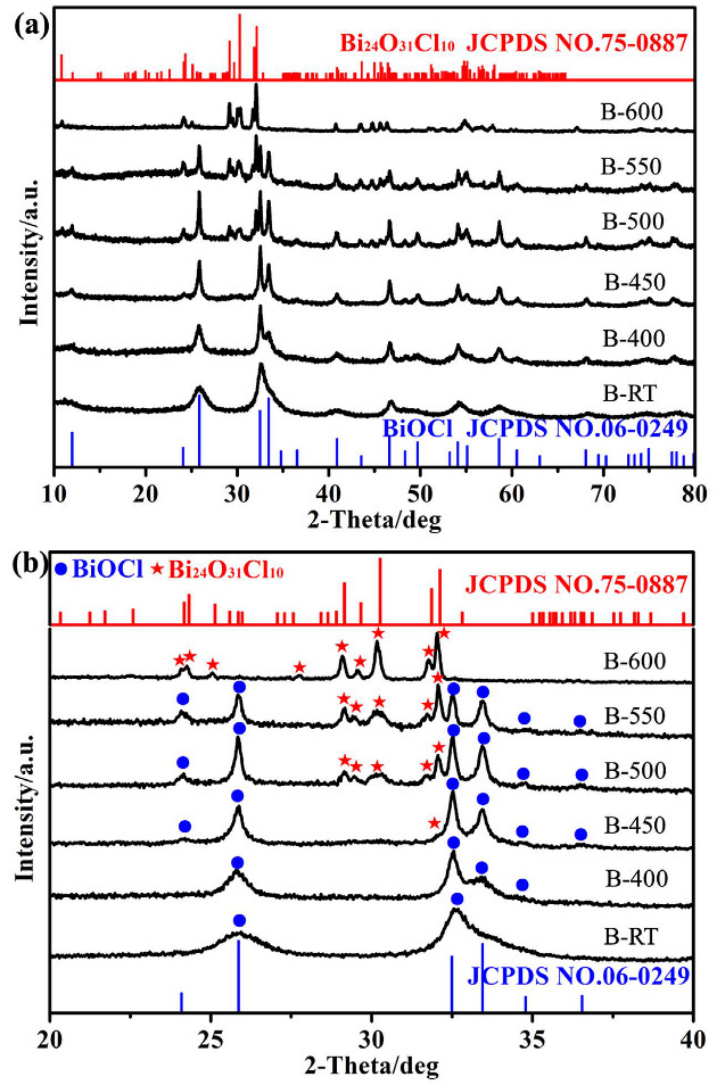

Figure 1. Wide and enlarged XRD patterns of various samples.

containing $\mathrm{BiOCl}$ and a narrow band-gap semiconductor has been intensively investigated, e.g. g- $\mathrm{C}_{3} \mathrm{~N}_{4} / \mathrm{BiOCl}^{25}$, $\mathrm{Bi}_{2} \mathrm{~S}_{3} / \mathrm{BiOCl}^{26}, \mathrm{BiOI} / \mathrm{BiOCl}^{27}, \mathrm{CdS} / \mathrm{BiOCl}^{28}$, $\mathrm{WO}_{3} / \mathrm{BiOCl}^{29}, \mathrm{BiVO}_{4} / \mathrm{BiOCl}^{30}, \mathrm{NaBiO}_{3} / \mathrm{BiOCl}^{31}$, etc. All these heterojunctions presented enhanced photocatalytic performances than their single-component counterparts.

From the viewpoint of solid state physics, details of the band edge potential are primarily determined by the static potential within the unit cell of a semiconductor ${ }^{32}$. Any symmetry and component perturbations can have consequence on the electronic structures and physical properties. Since the potential of conduction band minimum (CBM) and valence band maximum (VBM) are mainly related to $\mathrm{Bi} 6 \mathrm{p}$ and $\mathrm{Bi}$ 6s orbitals respectively, the regulation of CBM and VBM of bismuth-based semiconductors can be achieved by adjusting the Bi content ${ }^{33,34}$. Recently, nontypical stoichiometric semiconductors (NSSs), including $\mathrm{Bi}_{3} \mathrm{O}_{4} \mathrm{Cl}^{35}, \mathrm{Bi}_{12} \mathrm{O}_{15} \mathrm{Cl}_{6}{ }^{36}, \mathrm{Bi}_{24} \mathrm{O}_{31} \mathrm{Cl}_{10}{ }^{33}$ have been found to show visible light driven photocatalytic activities, which are regarded as ideal candidates for the construction of heterojunctions with $\mathrm{BiOCl}$. These NSSs have narrower band gap, faster transfer of charge carriers and more efficient separation of photogenerated electron-hole pairs ${ }^{37}$. Furthermore, they have the approximate crystalline architecture relative to their corresponding typical stoichiometric semiconductors (TSSs). As a nontypical stoichiometric bismuth-based semiconductor, $\mathrm{Bi}_{24} \mathrm{O}_{31} \mathrm{Cl}_{10}$ is widely known as a product of the thermal decomposition of $\mathrm{BiOCl}^{38}$. It has a narrow band gap of about $2.7 \sim 2.8 \mathrm{eV}^{33,39}$, demonstrating a good visible-light harvesting. Thus, $\mathrm{Bi}_{24} \mathrm{O}_{31} \mathrm{Cl}_{10} / \mathrm{BiOCl}$ heterojunction may be a promising photocatalyst in the visible light region, if both of them have the suitable $\mathrm{CB}$ and VB levels ${ }^{40}$.

In the present study, $\mathrm{Bi}_{24} \mathrm{O}_{31} \mathrm{Cl}_{10} / \mathrm{BiOCl}$ heterojunction was constructed via a in-situ fabrication. Although $\mathrm{Bi}_{24} \mathrm{O}_{31} \mathrm{Cl}_{10}$ is widely known as a thermal decomposition product of $\mathrm{BiOCl}$, the structure and the photocatalytic performance of the intermediate product $\mathrm{Bi}_{24} \mathrm{O}_{31} \mathrm{Cl}_{10} / \mathrm{BiOCl}$ heterojunction were not investigated in detail. The oxidation of benzyl alcohol to benzaldehyde is firstly chosen as the model reaction to check the photocatalytic performance of the $\mathrm{Bi}_{24} \mathrm{O}_{31} \mathrm{Cl}_{10} / \mathrm{BiOCl}$ heterojunction. The in-situ fabrication of $\mathrm{Bi}_{24} \mathrm{O}_{31} \mathrm{Cl}_{10} / \mathrm{BiOCl}$ heterojunction may predict more interfacial contact for efficient charge carriers separation ${ }^{37}$, resulting in highly enhanced photocatalytic performance toward benzyl alcohol oxidation.

\section{Results and Discussion}

Figure 1 displays the XRD patterns of $\mathrm{BiOCl}$ and the calcined samples. The XRD pattern of sample B-RT is assigned to tetragonal $\mathrm{BiOCl}$ (JCPDS NO. 06-0249). With an increase of annealing temperature, the XRD peaks belonging to $\mathrm{Bi}_{24} \mathrm{O}_{31} \mathrm{Cl}_{10}$ with a monoclinic structure (JCPDS NO. 75-0887) emerges. No apparent diffraction peaks belonging to $\mathrm{BiOCl}$ are observed when the temperature increased up to $600^{\circ} \mathrm{C}$. The enlarged XRD patterns of all samples in the range of $2 \theta=20 \sim 40^{\circ}$ are also presented to further verify the transformation process from tetragonal $\mathrm{BiOCl}$ to monoclinic $\mathrm{Bi}_{24} \mathrm{O}_{31} \mathrm{Cl}_{10}$ (Fig. 1b). A weak peak located at $32^{\circ}$ is assigned to $\mathrm{Bi}_{24} \mathrm{O}_{31} \mathrm{Cl}_{10}$ in XRD pattern of sample B-450. The other three typical strong peaks nearby $30^{\circ}$ are observed in sample $\mathrm{B}-500$, which 

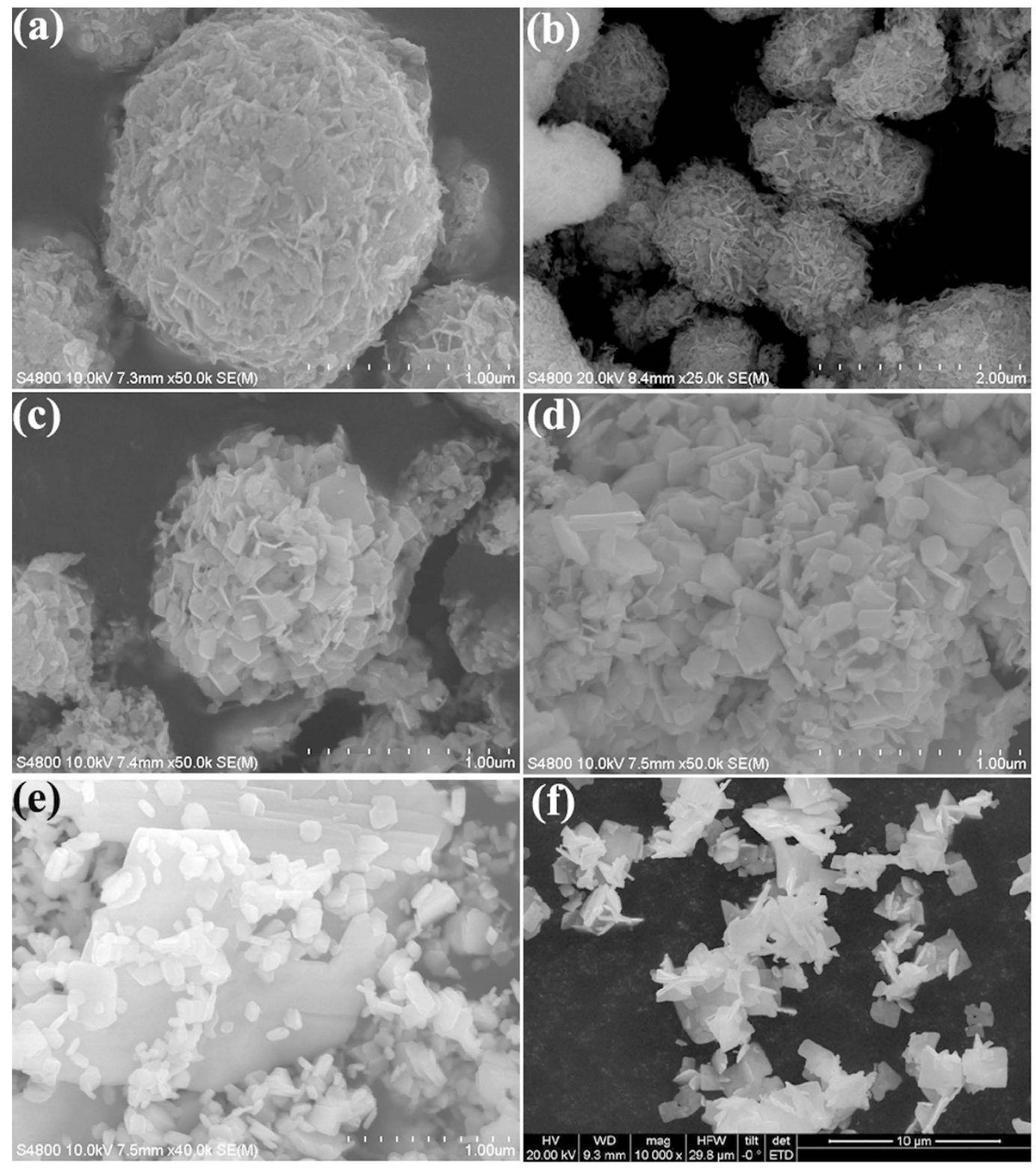

Figure 2. SEM images of B-RT (a), B-400 (b), B-450 (c), B-500 (d), B-550 (e), B-600 (f).

indicates that large amount of $\mathrm{Bi}_{24} \mathrm{O}_{31} \mathrm{Cl}_{10}$ is produced at reaction temperature of $500^{\circ} \mathrm{C}$. Further increase of reaction temperature induces the emergence of more diffraction peaks belonging to $\mathrm{Bi}_{24} \mathrm{O}_{31} \mathrm{Cl}_{10}$ and all the XRD peaks belonging to $\mathrm{Bi}_{24} \mathrm{O}_{31} \mathrm{Cl}_{10}$ phase are only left at $600^{\circ} \mathrm{C}(\mathrm{B}-600)$. On the other hand, no XRD peak of $\mathrm{Bi}_{24} \mathrm{O}_{31} \mathrm{Cl}_{10}$ phase is observed in sample $\mathrm{B}-400$, which may suggest that no observable phase transformation occurs or the $\mathrm{Bi}_{24} \mathrm{O}_{31} \mathrm{Cl}_{10}$ does not possess sufficient long-range order to be checked by XRD. DTA-TG curves (Figure S1) of sample B-RT shows that there is an exothermic peak at about $400^{\circ} \mathrm{C}$, suggesting that the phase transformation of $\mathrm{BiOCl}$ occurs as the temperature achieving to $400^{\circ} \mathrm{C}$, which result is consistent with the XRD results.

Figures 2 and S2 shows the SEM images of various samples. The image in Fig. 2a displays that the pure BiOCl spheres with diameter of about $1.5 \sim 2.0 \mu \mathrm{m}$ are mainly consisted of irregular nanosheets, which are $0.1 \sim 0.2 \mu \mathrm{m}$ in width and $3 \sim 5 \mathrm{~nm}$ in thickness (Figure S2a). After calcination at $400^{\circ} \mathrm{C}$, the nanosheet edges and angles of sample B-400 are distinct and differentiable (Fig. 2b). The gradual increased temperature leads to the morphological transformation from compact sphere to loose structure as well as irregular nanosheets to square analogs (Fig. 2c,d). Furthermore, the nanosheets of BiOCl become wider and thicker with an increase of annealing temperature. Sample B-600 (pure $\mathrm{Bi}_{24} \mathrm{O}_{31} \mathrm{Cl}_{10}$ ) presents square-like plate structure with $1 \sim 2 \mu \mathrm{m}$ in width and $\sim 0.1 \mu \mathrm{m}$ in thickness (Figs $2 \mathrm{f}$ and $\mathrm{S} 2 \mathrm{~b}$ ). It could also be observed that the sheet-shaped structure with narrower width and thinner thickness decreases, while the plate-shaped structure increases by elevating the annealing temperature, which result is consistent with the BET results (Figure S3) that sample B-600 has the lower specific surface area $\left(S_{\mathrm{BET}}\right)$ than sample B-RT. 

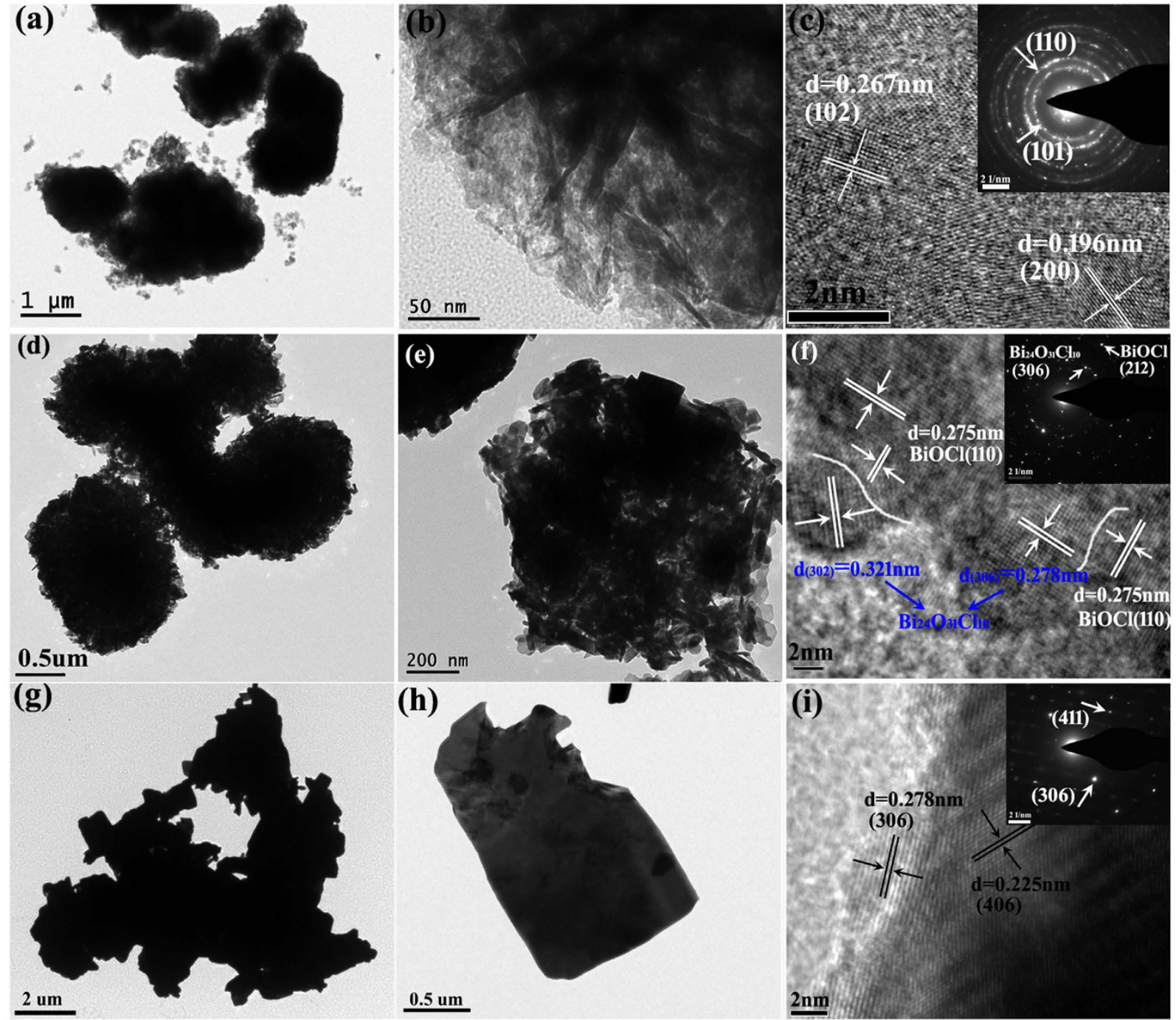

(h)

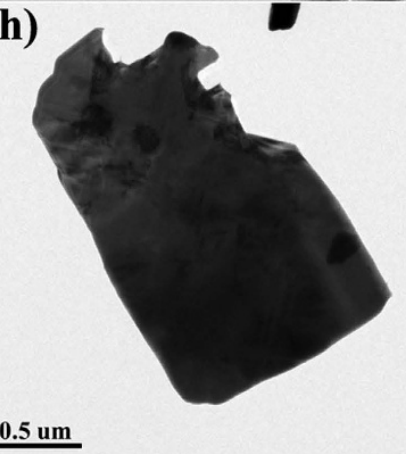

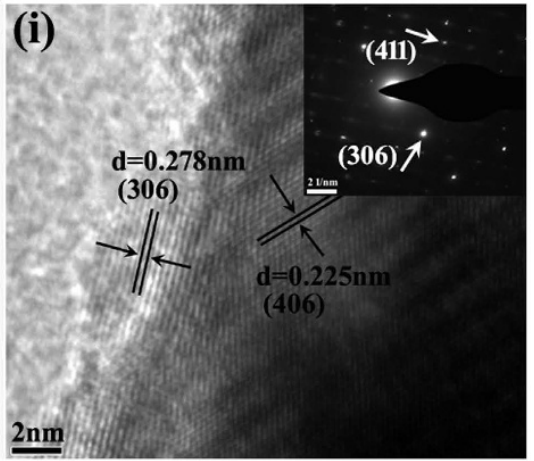

Figure 3. TEM, HRTEM images and SAED patterns of samples B-RT(a-c), B-450 (d-f) and B-600 (g-i).

The detailed morphologies, crystal structures and the heterojunction features of samples B-RT, B-450 and B-600 are characterized by TEM, HRTEM and SAED. Figure 3a,b reveal that BiOCl spheres are composed of irregular nanosheets, which is consistent with the SEM observation (Fig. 2a). HRTEM image in Fig. 3c discloses that the distances between the adjacent lattice fringes are about 0.267 and $0.196 \mathrm{~nm}$, matching well with the (102) and (200) crystalline plane of $\mathrm{BiOCl}$, respectively. The selected area electron diffraction (SAED) (Inset of Fig. 3c) clearly presents the crystalline planes of (101) and (110) of BiOCl, respectively. Sample B-450 keeps the same diameter, but the shape of the nanosheets becomes regular (Fig. 3d,e). Figure $3 \mathrm{f}$ provides a comprehensive information of the $\mathrm{Bi}_{24} \mathrm{O}_{31} \mathrm{Cl}_{10} / \mathrm{BiOCl}$ heterojunction. The lattice fringes with the $d$ spacing of $0.275 \mathrm{~nm}$ correspond to the (110) crystalline plane of $\mathrm{BiOCl}$, whereas the lattice fringes with the $d$ spacing of 0.321 and $0.278 \mathrm{~nm}$ belong to the (30-2) and (306) crystalline plane of $\mathrm{Bi}_{24} \mathrm{O}_{31} \mathrm{Cl}_{10}$, respectively. Furthermore, as displayed in Fig. $3 \mathrm{f}$ that there exists an identifiable interface (presented by white line) and continuity of the lattice fringes between $\mathrm{BiOCl}$ and $\mathrm{Bi}_{24} \mathrm{O}_{31} \mathrm{Cl}_{10}$, indicating the formation of a heterojunction between the two semiconductors. The SAED pattern (Inset of Fig. 3f) further confirms the coexistence of $\mathrm{BiOCl}$ and $\mathrm{Bi}_{24} \mathrm{O}_{31} \mathrm{Cl}_{10}$. Figure $3 \mathrm{~g}$, h reveal that sample $\mathrm{B}-600$ displays a square-like structure and no apparent $\mathrm{BiOCl}$ spheres are observed. Both the HRTEM image and the SAED pattern in Fig. $3 \mathrm{i}$ indicate the single-crystalline characteristic of $\mathrm{Bi}_{24} \mathrm{O}_{31} \mathrm{Cl}_{10}$.

To further confirm the chemical state and chemical composition of the as-prepared samples, X-ray photoelectron spectroscopy (XPS) analysis was applied and the results are shown in Fig. 4. The survey scans of samples B-RT, B-450 and B-600 distinctly reveal the co-existence of $\mathrm{Bi}, \mathrm{O}$ and $\mathrm{Cl}$ elements without other impurities, excluding adventitious carbon-based contaminant. The two primary peaks at $\sim 159.0 \mathrm{eV}$ and $\sim 164.0 \mathrm{eV}$ in $\mathrm{Bi} 4 \mathrm{f}$ XPS spectra result from the spin orbital splitting photoelectrons of $B i 4 f_{7 / 2}$ and $B i 4 f_{5 / 2}$, respectively ${ }^{41}$. There is an obvious red-shift in the $\mathrm{Bi} 4 \mathrm{f}$ binding energy with increasing the temperature to $600^{\circ} \mathrm{C}$. Variations in the elemental binding energies are generally related to the difference in chemical potential and polarizability of involved elements ${ }^{42,43}$. Thus, the binding energy shift in sample B-450 is possibly attributed to the interaction between $\mathrm{BiOCl}$ and $\mathrm{Bi}_{24} \mathrm{O}_{31} \mathrm{Cl}_{10}$, which result is similar to the $\mathrm{SnO}_{2-\mathrm{x}} / \mathrm{g}_{-} \mathrm{C}_{3} \mathrm{~N}_{4}{ }^{44}$ and $\mathrm{TiO}_{2} / \mathrm{ZnPcGly}{ }^{45}$. It is reported that the 

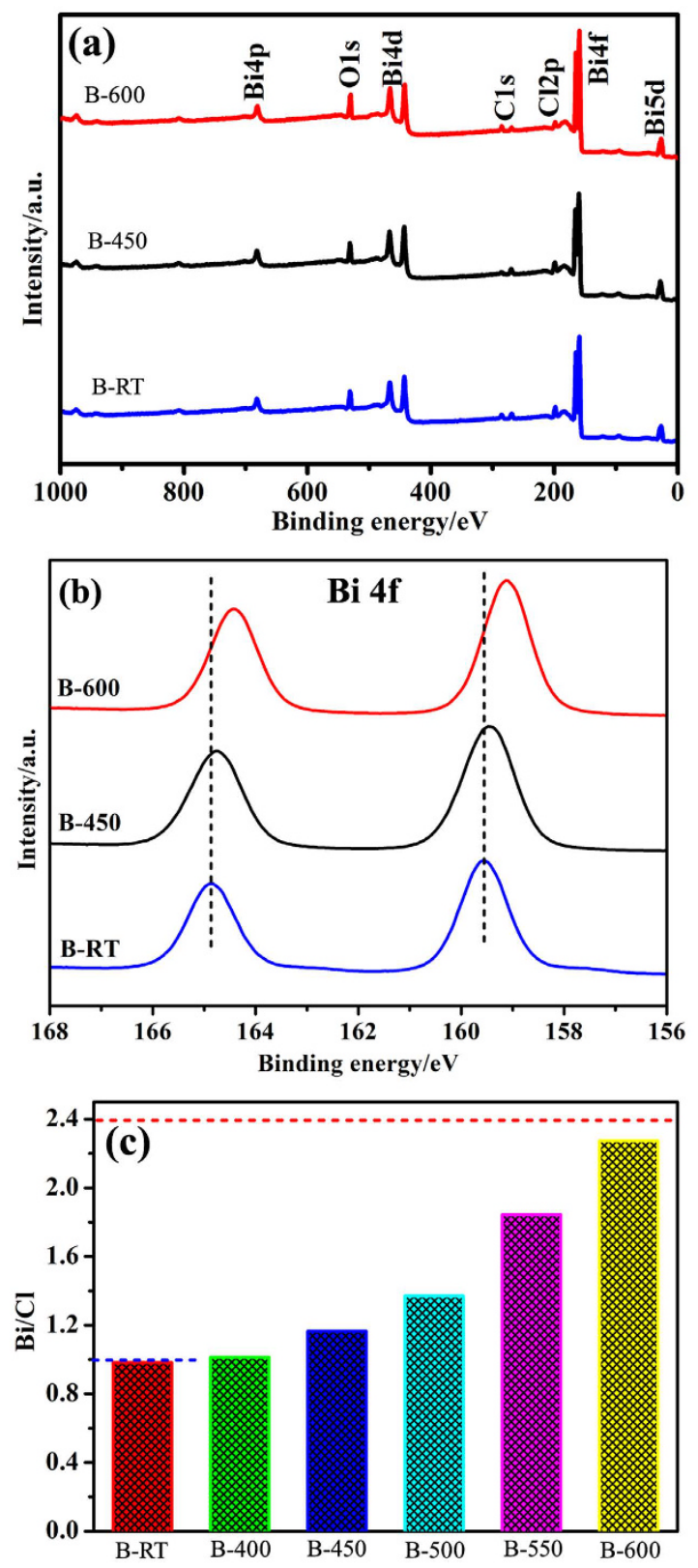

Figure 4. XPS survey spectra (a) and high-resolution XPS spectra for Bi $4 \mathrm{f}(\mathbf{b})$ of samples B-RT, B-450 and $\mathrm{B}-600$, and the variation of $\mathrm{Bi} / \mathrm{Cl}$ molar ratio as a function of reaction temperature $(\mathbf{c})$. The blue and red dash lines are the theoretical values of $\mathrm{Bi} / \mathrm{Cl}$ molar ratio for pure $\mathrm{BiOCl}$ and $\mathrm{Bi}_{24} \mathrm{O}_{31} \mathrm{Cl}_{10}$, respectively.

increase or decrease in electron concentration could enhance or reduce the electron screening effect, which would weaken or strengthen the binding energy ${ }^{46}$. The higher electronegativity of Bi could induce increased electron concentration in the new formed bond ${ }^{37}$, such as $\mathrm{Bi}-\mathrm{Cl}$ or/and $\mathrm{Bi}-\mathrm{O}$ bands at the interface, which enhances the electron screening effect and leads to the $\mathrm{Bi} 4 \mathrm{f}$ peaks shift toward lower binding energy. Furthermore, the position of $\mathrm{Bi} 4 \mathrm{f}$ peaks in sample $\mathrm{B}-600$ is also different from that in sample B-RT, which could be attributed to the different chemical environment of $\mathrm{Bi}$ ions in $\mathrm{BiOCl}$ and $\mathrm{Bi}_{24} \mathrm{O}_{31} \mathrm{Cl}_{10}$. This observation is in accordance with the XPS results of $\mathrm{BiOCl} / \mathrm{Bi}_{12} \mathrm{O}_{15} \mathrm{C}_{16}{ }^{36}$ and $\mathrm{BiVO}_{4} / \mathrm{Bi}_{4} \mathrm{~V}_{2} \mathrm{O}_{11}{ }^{37}$. However, the span between the two binding energy peaks maintains the same value of $5.3 \mathrm{eV}$, which suggests that $\mathrm{Bi}$ exists in the chemical state of $\mathrm{Bi}^{3+}$ in both $\mathrm{BiOCl}$ and $\mathrm{Bi}_{24} \mathrm{O}_{31} \mathrm{Cl}_{10}$.

The chemical compositions of $\mathrm{Bi}, \mathrm{Cl}$ and $\mathrm{O}$ in various samples as well as the variation of $\mathrm{Bi} / \mathrm{Cl}$ molar ratio as a function of annealing temperature are displayed in Fig. 4c and Table S1. As shown in Fig. 4c, there exists a monotonic increase of $\mathrm{Bi} / \mathrm{Cl}$ molar ratio with an increase of annealing temperature. When the temperature increases to $600^{\circ} \mathrm{C}$, the $\mathrm{Bi} / \mathrm{Cl}$ molar ratio reaches 2.295 , which is very close to the theoretical value 2.4 of $\mathrm{Bi}_{24} \mathrm{O}_{31} \mathrm{Cl}_{10}$. This observation indicates the phase transformation from pure $\mathrm{BiOCl}$ to $\mathrm{Bi}_{24} \mathrm{O}_{31} \mathrm{Cl}_{10}$. It could be possibly accepted that if the $\mathrm{Bi} / \mathrm{Cl}$ molar ratio is larger than the theoretical value of $\mathrm{BiOCl}$, the phase transformation occurs. Thus, $450^{\circ} \mathrm{C}$ could be recognized as the initial phase transformation temperature in our experiment, which is consistent with the XRD result. 

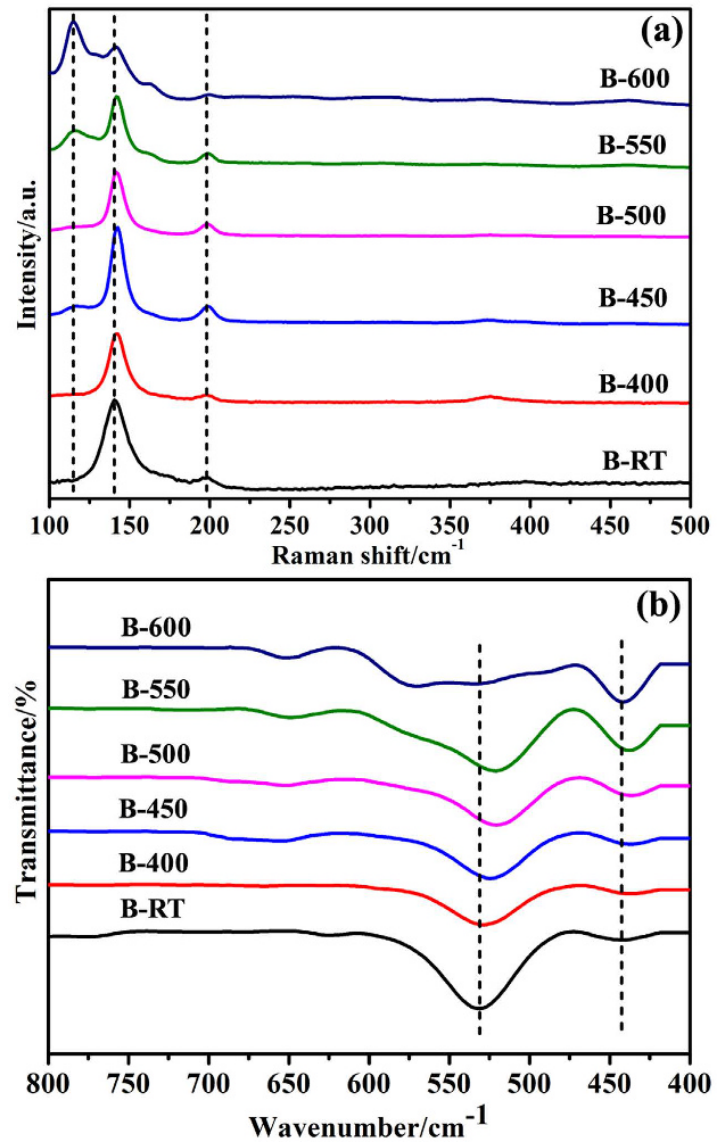

Figure 5. Raman spectra (a) and FT-IR spectra (b) of various samples.

Raman and FT-IR measurements are performed to investigate the $\mathrm{BiOCl}$ phase transformation and interfacial interactions between $\mathrm{BiOCl}$ and $\mathrm{Bi}_{24} \mathrm{O}_{31} \mathrm{Cl}_{10}$. For sample B-RT (Fig. 5a), there are two distinguishable Raman active bands at $140 \mathrm{~cm}^{-1}$ and $198 \mathrm{~cm}^{-1}$ which are assigned to the $\mathrm{A}_{1 \mathrm{~g}}$ and $\mathrm{E}_{\mathrm{g}}$ internal $\mathrm{Bi}-\mathrm{Cl}$ stretching modes ${ }^{47,48}$, respectively. However, the band related to the motion of oxygen atoms at about $400 \mathrm{~cm}^{-136,49}$ is very weak and nearly unnoticeable. With an increase of annealing temperature, the Raman peak assigned to $\mathrm{A}_{1 \mathrm{~g}}$ shifts to higher wavenumbers. This phenomenon could be ascribed to the formation of heterojunction between $\mathrm{BiOCl}$ and $\mathrm{Bi}_{24} \mathrm{O}_{31} \mathrm{Cl}_{10}$, because the interfacial contact might produce intrinsic stresses on the crystal structure and alter the periodicity of the lattice ${ }^{37,50}$. However, for sample B-600, there exists a new band located at $115 \mathrm{~cm}^{-1}$, which is close to that of pure $\mathrm{Bi}_{24} \mathrm{O}_{31} \mathrm{Cl}_{10}$ (Figure $\left.\mathrm{S} 4\right)^{33}$, suggesting the presence of $\mathrm{Bi}_{24} \mathrm{O}_{31} \mathrm{Cl}_{10}$ in sample $\mathrm{B}-600$.

Figures $5 \mathrm{~b}$ and S5 show the FT-IR spectra of samples B-RT $\sim \mathrm{B}-600$. For sample B-RT, the peaks at $3437 \mathrm{~cm}^{-1}$ and $1622 \mathrm{~cm}^{-1}$ in Figure S5 are assigned to the stretching vibration and deformation vibration of the hydroxyl group $(-\mathrm{OH})$ acquired from the wet atmosphere ${ }^{51}$. The band at $2925 \mathrm{~cm}^{-1}$ represents the $\mathrm{C}-\mathrm{H}$ stretching vibration $^{52}$, which originates from glycerol in the synthetic procedure of $\mathrm{BiOCl}$. The bands striding over the wavenumbers 1036 to $1406 \mathrm{~cm}^{-1}$ are ascribed to the stretching vibration of the C-O-C bond in glycerol ${ }^{52}$. The bands located between $200 \sim 800 \mathrm{~cm}^{-1}$ correspond to the characteristic of Bi-O bond, and the peak at about $523 \mathrm{~cm}^{-1}$ resulted from the symmetrical stretching vibration of the $\mathrm{Bi}-\mathrm{O}$ band is a typical peak of $\mathrm{BiOCl}^{51,53,54}$. With an increase of the annealing temperature, the weakening of the bands assigned to $-\mathrm{OH}, \mathrm{C}-\mathrm{H}$ and $\mathrm{C}-\mathrm{O}-\mathrm{C}$ is attributed to the gradual removal of adsorbed water and glycerol (Figure S5). Furthermore, it can be identified in Fig. $5 \mathrm{~b}$ that the band at $523 \mathrm{~cm}^{-1}$ exhibits a blue shift and the peak located at $442 \mathrm{~cm}^{-1}$ is gradually distinguishable, verifying the interfacial interactions caused by the construction of the heterojunction between $\mathrm{BiOCl}$ and $\mathrm{Bi}_{24} \mathrm{O}_{31} \mathrm{Cl}_{10}$ as well as the dominant existence of $\mathrm{Bi}_{24} \mathrm{O}_{31} \mathrm{Cl}_{10}$, which result is similar to that of $\mathrm{BiVO}_{4} / \mathrm{Bi}_{4} \mathrm{~V}_{2} \mathrm{O}_{11}{ }^{37}$. Based on the results from HRTEM, XPS, Raman and FT-IR spectra, it could be concluded that the $\mathrm{Bi}_{24} \mathrm{O}_{31} \mathrm{Cl}_{10} / \mathrm{BiOCl}$ heterojunction is successfully constructed, which is probably helpful for the transfer and separation of photogenerated charge carriers as well as the improvement of photocatalytic activity.

The photocatalytic performance of catalysts is related to the light absorption, thus the UV-vis diffuse reflectance spectroscopy (DRS) was adopted to determine the visible light harvesting ability of $\mathrm{BiOCl}$ and calcined samples (Fig. 6a). BiOCl presents almost no absorption in the visible light region with an absorption edge at $360 \mathrm{~nm}$. Interestingly, there exists a red shift of the absorption edge with an increase of the annealing temperature, and the sample B-600 (pure $\mathrm{Bi}_{24} \mathrm{O}_{31} \mathrm{Cl}_{10}$ ) possesses the most intense visible light harvesting ability with an absorption edge at about $455 \mathrm{~nm}$. It should be noted that samples B-500 and B-550 exhibit similar absorption feature in comparison with pure $\mathrm{Bi}_{24} \mathrm{O}_{31} \mathrm{Cl}_{10}$ (B-600), this result is in accordance with the XRD result that massive 

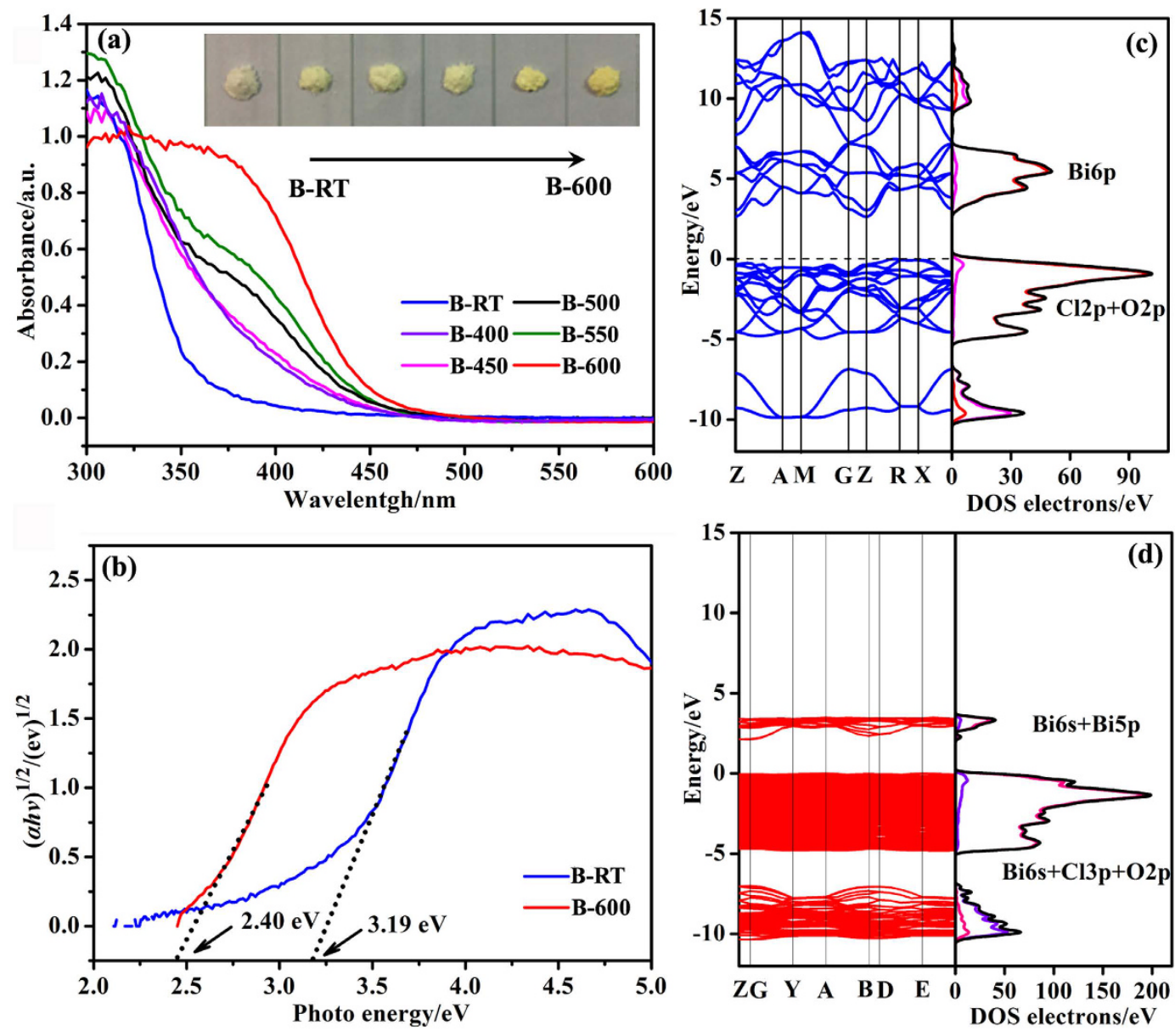

Figure 6. UV-vis diffuse reflectance spectra (DRS) (a) and plots of $(\alpha h v)^{1 / 2}$ vs. the photo energy $(h v)(\mathbf{b})$ for samples, calculated band structure and density of states (DOS) of $\mathrm{BiOCl}(\mathbf{c})$ and $\mathrm{Bi}_{24} \mathrm{O}_{31} \mathrm{Cl}_{10}(\mathbf{d})$.

$\mathrm{Bi}_{24} \mathrm{O}_{31} \mathrm{Cl}_{10}$ phase exists in sample B-500. The new emerged absorption edge also indicates that $\mathrm{Bi}_{24} \mathrm{O}_{31} \mathrm{Cl}_{10} / \mathrm{BiOCl}$ heterojunction photocatalyst should display visible light photocatalytic activity. The UV-vis spectra result is also confirmed by the colors of $\mathrm{BiOCl}(\mathrm{B}-\mathrm{RT})$ and calcined samples (B-400 B-600), changing from white to yellow, as shown in inserted graph in Fig. 6 a.

It is accepted that the band gap energy of a semiconductor can be evaluated by the following equation:

$$
\alpha h v=A\left(h v-E_{g}\right)^{n / 2}
$$

where $\alpha, v, E_{\mathrm{g}}$, and $A$ are the absorption coefficient, light frequency, band gap energy, and a constant, respectively. The parameter $n$ is determined by the characteristics of the transition in a semiconductor (i.e., $\mathrm{n}=1$ for direct transition or $n=4$ for indirect transition). In order to specify the $n$ values of $\mathrm{BiOCl}$ and $\mathrm{Bi}_{24} \mathrm{O}_{31} \mathrm{Cl}_{10}$, the density functional theory (DFT) calculations are carried out (Fig. 6c,d). The calculated Fermi level is set at an energy of zero $\mathrm{eV}$ in the band gap, indicating typical intrinsic semiconducting characteristics in the electronic structure. Fig. $6 \mathrm{c}$ (left) shows that the conduction band minimum (CBM) and the valence band maximum (VBM) are located at $\mathrm{Z}$ and $\mathrm{R}$ point, respectively. It indicates that $\mathrm{BiOCl}$ is an indirect band gap semiconductor with a band gap of $2.63 \mathrm{eV}$, which is close to the previous DFT calculations ${ }^{55,56}$. The calculated band structure and density of states (DOS) (Fig. 6c right) imply that the $\mathrm{CB}$ of BiOCl mainly consists of Bi6p orbitals, whereas the VB is contributed by hybridized $\mathrm{Cl} 2 \mathrm{p}$ and $\mathrm{O} 2 \mathrm{p}$ orbitals. It could be inferred from Fig. $6 \mathrm{~d}$ that $\mathrm{Bi}_{24} \mathrm{O}_{31} \mathrm{Cl}_{10}$ is also an indirect band gap semiconductor with a band gap of $2.11 \mathrm{eV}$, which is consistent with the previous DFT calculations ${ }^{39}$. The $\mathrm{CB}$ of $\mathrm{Bi}_{24} \mathrm{O}_{31} \mathrm{Cl}_{10}$ mainly consists of Bi6s and Bi5p orbitals, whereas the VB has major contribution from the hybridized $\mathrm{Bi} 6 \mathrm{~s}, \mathrm{Cl} 3 \mathrm{p}$ and $\mathrm{O} 2 \mathrm{p}$ orbitals.

Having these results in mind, the $n$ values for both $\mathrm{BiOCl}$ and $\mathrm{Bi}_{24} \mathrm{O}_{31} \mathrm{Cl}_{10}$ are 4 . Thus, the band gap energies of pure $\mathrm{BiOCl}$ and $\mathrm{Bi}_{24} \mathrm{O}_{31} \mathrm{Cl}_{10}$ could be estimated from a plot of $(\alpha h v)^{1 / 2}$ versus the photon energy $(h v)$. The intercept of the tangent to the $\mathrm{x}$-axis will give a good approximation of the band gap energies for various samples. As shown in Fig. 6b, the optical band gaps of sample B-RT and B-600 are calculated to be $3.19 \mathrm{eV}$ and $2.40 \mathrm{eV}$, respectively, which are close to the previously reported values ${ }^{33,40,57}$. 

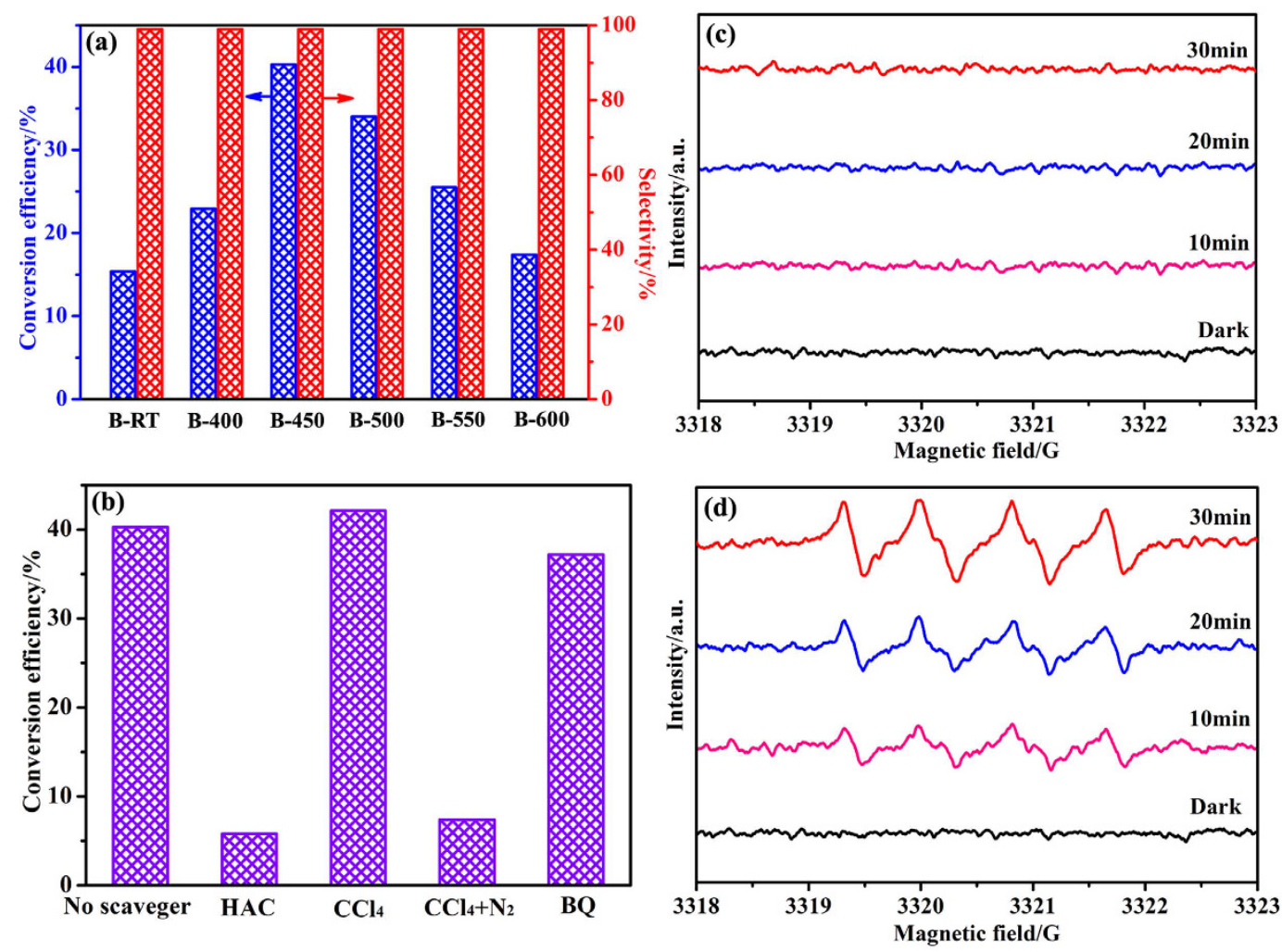

Figure 7. Photocatalytic conversion of benzyl alcohol over various samples under visible light irradiation (a), effects of scavengers on the conversion of benzyl alcohol (b), DMPO spin-trapping ESR spectra of sample B-450 in methanol dispersion for DMPO-OH (c) and in $20 \%$ methanol $+80 \%$ methylbenzene dispersion for DMPO$\mathrm{O}_{2}^{-}(\mathbf{d})$.

It is accepted that the selective photocatalytic oxidation of benzyl alcohol to benzaldehyde using $\mathrm{O}_{2}$ as the oxidizing agent is considered as a model reaction to evaluate the photocatalytic performance of semiconductors ${ }^{58}$. Figure 7a displays the benzyl alcohol conversion efficiency over various samples. Notably, all samples exhibit photocatalytic activities toward benzyl alcohol oxidation under visible light irradiation. It's noted that pure $\mathrm{BiOCl}$ (B-RT) with a band gap of $3.19 \mathrm{eV}$ also shows a benzyl alcohol conversion efficiency of $15.4 \% . \mathrm{TiO}_{2}$, as a wide band-gap semiconductor, also displays excellent conversion efficiency $(>99 \%)$ and selectivity $(>99 \%)$ toward benzyl alcohol oxidation under visible light irradiation. This phenomenon is ascribed to the corresponding absorption edge shifts and absorption intensity enhancement in the visible-light region, which is related to the formation of a visible-light responsive charge-transfer complex between $\mathrm{TiO}_{2}$ and benzyl alcohol ${ }^{18,19}$. To specify the reason that $\mathrm{BiOCl}$ exhibits visible light photocatalytic activity toward benzyl alcohol oxidation, UV-vis absorption spectra of benzyl alcohol (BA)-adsorbed samples are investigated (Figure S6). As illustrated in Figure S6, there is nearly no obvious changes in absorption edges and intensities in visible-light region for both BA-adsorbed samples and bare samples. Thus, it is expected that the benzyl alcohol conversion efficiency over the present samples may be not related to the charge-transfer complex formed between photocatalysts and benzyl alcohol. The photocatalytic activity of $\mathrm{BiOCl}$ under visible light irradiation may be related to the special nanosheet structure and $V_{\mathrm{Bi}}^{\prime \prime \prime} V_{\mathrm{O}} V_{\mathrm{Bi}}^{\prime \prime \prime}$ vacancy associates in $\mathrm{BiOCl}^{23,59}$. The conversion efficiency reaches a maximum of approximately $40.3 \%$ with increasing the annealing temperature to $450{ }^{\circ} \mathrm{C}$, however, further increase of the annealing temperature leads to an obvious decrease in the conversion efficiency. Furthermore, all samples display $>99 \%$ selectivity toward benzaldehyde. Although the photocatalytic performance of the as-prepared $\mathrm{Bi}_{24} \mathrm{O}_{31} \mathrm{Cl}_{10} /$ $\mathrm{BiOCl}$ heterojunction is lower than that of $\mathrm{TiO}_{2}$ and $\mathrm{Na}_{x} \mathrm{TaO}_{y} \cdot n \mathrm{H}_{2} \mathrm{O}^{1,19}$, it is close to even higher than several oxyhalides, such as $\mathrm{Bi}_{3} \mathrm{O}_{4} \mathrm{Br}, \mathrm{BiOBr}$ and $\mathrm{Bi}_{12} \mathrm{O}_{17} \mathrm{Cl}_{2}{ }^{7}$ (Table S2), suggesting comprehensive work needs to be further conducted for oxyhalide semiconductors in the future.

It is well known that the photocatalytic process involves the photogenerated electrons and holes, which could react with the molecular $\mathrm{O}_{2}$ and $\mathrm{H}_{2} \mathrm{O} / \mathrm{HO}^{-}$to yield superoxide radical $\left(\mathrm{O}_{2}^{-}\right)$and $\mathrm{OH}$, respectively. The new produced active species are essentially important in the catalytic reactions. To reveal the origin of the highly photocatalytic performance and selectivity for the $\mathrm{Bi}_{24} \mathrm{O}_{31} \mathrm{Cl}_{10} / \mathrm{BiOCl}$ heterojunction, a series of active species trapping experiments were further conducted and the results are displayed in Fig. 7b. When acetic acid (HAC) as holes scavenger is added, the conversion efficiency of benzyl alcohol decreases significantly. The addition of tetrachloromethane $\left(\mathrm{CCl}_{4}\right)$ and benzoquinone (BQ) used as an electron and superoxide radical scavenger respectively, makes a slight influence in the conversion efficiency. These observations suggest that photogenerated holes act as the dominant role in the photocatalytic conversion of benzyl alcohol. Moreover, if molecular nitrogen is used instead of molecular $\mathrm{O}_{2}$ in the presence of $\mathrm{CCl}_{4}$ during the photocatalytic process, the conversion efficiency 
surprisingly decreases, which suggests that molecular $\mathrm{O}_{2}$ is specially vital in the photocatalytic reaction. That is to say, the generation of superoxide radicals, which consumes lots of the photogenerated electrons, could greatly inhibit the recombination of photogenerated charge carriers, favoring the selective oxidation of benzyl alcohol to benzaldehyde originated by photogenerated holes.

The above result could also be proved by ESR technique. DMPO spin-trapping ESR spectra of sample B- 450 to reveal the generation of active species $\mathrm{O}_{2}^{-}$and $\mathrm{OH}$ are displayed in Fig. $7 \mathrm{c}$ and d. As shown in Fig. 7c, no characteristic ESR signal is detected either in the dark or in the visible light irradiation from $10 \mathrm{~min}$ to $30 \mathrm{~min}$, indicating that $\mathrm{OH}$ is not involved in the photocatalytic process. In Fig. 7d, there is no characteristic ESR signal observed in dark. However, the characteristic peaks of DMPO- $\mathrm{O}_{2}{ }^{-}$adduct are detected after $10 \mathrm{~min}$ of visible light irradiation. Furthermore, the intensity of the $\mathrm{DMPO}-\mathrm{O}_{2}{ }^{-}$signals increases with prolonging the irradiation time.

Combining the results of scavengers experiment and ESR spectra, it could be concluded that the photogenerated holes are the major active species in the photocatalytic conversion of benzyl alcohol under visible light irradiation, the active species $\mathrm{O}_{2}^{-}$are indeed formed during the photocatalytic process but not involved in the photocatalytic reaction. For potential applications, the stability of the heterojunction photocatalyst should be taken into consideration. Figure S7 presents the XRD patterns of sample B- 450 before and after photocatalytic process. There is no structural variation between the samples before and after catalytic reaction, indicating the strong structural stability of $\mathrm{Bi}_{24} \mathrm{O}_{31} \mathrm{Cl}_{10} / \mathrm{BiOCl}$ heterojunction.

To investigate the photocatalytic process in detail, the relative conduction band $(\mathrm{CB})$ and valence band $(\mathrm{CB})$ potentials of the semiconductors should be determined. The Mott-Schottky plots of B-RT (BiOCl) and B-600 $\left(\mathrm{Bi}_{24} \mathrm{O}_{31} \mathrm{Cl}_{10}\right)$ are shown in Figure S8. It is found that the flat-band potential $\left(V_{\mathrm{fb}}\right)$ of $\mathrm{BiOCl}$ and $\mathrm{Bi}_{24} \mathrm{O}_{31} \mathrm{Cl}_{10}$ are determined to be 0.46 and $-0.33 \mathrm{~V}$ versus $\mathrm{Ag} / \mathrm{AgCl}$ (equivalent to 0.68 and $-0.11 \mathrm{~V}$ versus $\mathrm{NHE}$ ) through extrapolating the linear parts of the Mott-Schottky plots to potential axis, respectively. It is generally known that the conduction band potentials $\left(E_{\mathrm{CB}}\right)$ of $\mathrm{n}$-type semiconductors are very close to $(0.1 \sim 0.2 \mathrm{eV}$ more negative $)$ the flat-band potentials ${ }^{60}$. Thus, we could deduce that the $\mathrm{CB}$ position of $\mathrm{Bi}_{24} \mathrm{O}_{31} \mathrm{Cl}_{10}(-0.21 \mathrm{eV})$ is more negative than that of $\mathrm{BiOCl}(0.58 \mathrm{eV})$. The schematic band diagrams of pure $\mathrm{BiOCl}$ and $\mathrm{Bi}_{24} \mathrm{O}_{31} \mathrm{Cl}_{10}$ are illustrated in Fig. $8 \mathrm{a}$.

The charge transfer in the $\mathrm{Bi}_{24} \mathrm{O}_{31} \mathrm{Cl}_{10} / \mathrm{BiOCl}$ heterojunction is depicted in Fig. 8b. The electrons are excited from $\mathrm{VB}$ of $\mathrm{Bi}_{24} \mathrm{O}_{31} \mathrm{Cl}_{10}$ to the $\mathrm{CB}$ potential position $(-0.21 \mathrm{eV})$ under visible light irradiation, but the electrons in the $\mathrm{VB}$ of $\mathrm{BiOCl}$ could not be excited because of its wide band gap. Partial photogenerated electrons transfer to the $\mathrm{CB}$ of $\mathrm{BiOCl}$ and the other part would be trapped by $\mathrm{O}_{2}$ to produce $\mathrm{O}_{2}^{-}$radicals because of the less redox potential $(-0.16 \mathrm{eV})^{61}$ of $\mathrm{O}_{2} /{ }^{\bullet} \mathrm{O}_{2}^{-}$. The photogenerated holes in the $\mathrm{VB}$ of $\mathrm{Bi}_{24} \mathrm{O}_{31} \mathrm{Cl}_{10}$ react with benzyl alcohol and convert them to benzaldehyde. The generation of $\mathrm{O}_{2}{ }^{-}$radicals greatly inhibits the recombination of photogenerated charge carriers, which is favorable for the photocatalytic performance.

To confirm the efficient separation of photogenerated charge carriers, photocurrent transient response measurements of sample B-RT, B-450 and B-600 are performed (Fig. 8c). As shown in Fig. 8c, all samples are prompt in producing photocurrent with a reproducible response to on/off cycle under visible light irradiation, suggesting that absorption of light could produce the photo-induced charge carriers and the charge carriers could transfer effectively. In comparison with B-RT and B-600, the sample B-450 displays the strongest peak intensity, implying more excellent photocatalytic activity of the $\mathrm{Bi}_{24} \mathrm{O}_{31} \mathrm{Cl}_{10} / \mathrm{BiOCl}$ heterojunction than the sole semiconductor counterparts.

\section{Conclusions}

$\mathrm{A} \mathrm{Bi}_{24} \mathrm{O}_{31} \mathrm{Cl}_{10} / \mathrm{BiOCl}$ heterojunction has been successfully constructed through a simple thermal annealing route. Various characterization techniques confirm the construction of the $\mathrm{Bi}_{24} \mathrm{O}_{31} \mathrm{Cl}_{10} / \mathrm{BiOCl}$ heterojunction during the annealing process. The obtained $\mathrm{Bi}_{24} \mathrm{O}_{31} \mathrm{Cl}_{10} / \mathrm{BiOCl}$ photocatalyst displays excellent photocatalytic efficiency and selectivity toward the conversion of benzyl alcohol to benzaldehyde under visible light irradiation, which could reach $40.3 \%$ and $>99 \%$, respectively. The photogenerated holes play an important role in the photocatalytic oxidation of benzyl alcohol and superoxide radicals are not involved in the photocatalytic process. The in-situ generation of heterojunction photocatalysts may provide superior interfacial contact, which is advantageous for enhancing the photocatalytic performance.

\section{Methods}

$\mathrm{Bi}_{24} \mathrm{O}_{31} \mathrm{Cl}_{10} / \mathrm{BiOCl}$ heterojunction synthesis. All chemical solvents and reagents were analytical grade and were used without further purification. In a typical procedure, $0.776 \mathrm{~g} \mathrm{Bi}\left(\mathrm{NO}_{3}\right)_{3} \cdot 5 \mathrm{H}_{2} \mathrm{O}$ was dissolved in $76 \mathrm{~mL}$ of glycerol, denoted as solution A. Then, $0.12 \mathrm{~g} \mathrm{KCl}$ was dissolved in $4 \mathrm{~mL}$ of deionized water (solution B), which was subsequently poured into solution A. After stirring for $15 \mathrm{~min}$, the mixture was transferred into a $100 \mathrm{~mL}$ Teflon-lined stainless steel autoclave, heated to $110^{\circ} \mathrm{C}$ and kept at this temperature for $8 \mathrm{~h}$. The resulting precipitate was collected by centrifugation, then washed with ethanol and deionized water for several times, and dried at $80^{\circ} \mathrm{C}$ in vacuum to obtain the pure $\mathrm{BiOCl}$ powder (denoted as B-RT).

The thermal annealing step was performed in an air-atmosphere programmable tube furnace in the temperature range of $400 \sim 600^{\circ} \mathrm{C}$ with an interval of $50^{\circ} \mathrm{C}$. The final products were denoted as B- $400 \sim \mathrm{B}-600$, respectively.

\section{Characterization}

Detailed crystallographic information of the synthesized samples was obtained on an X-ray diffractometer (Empypean Panalytical) with $\mathrm{Cu} \mathrm{K} a$ radiation $(\lambda=0.15406 \mathrm{~nm})$. The thermogravinetric analysis (TG) and differential thermal analysis (DTA) were carried out on a thermal analyzer (NETZSCH STA 449F3) where the sample was heated from 30 to $950^{\circ} \mathrm{C}$ with a raising ramp rate of $10^{\circ} \mathrm{C} / \mathrm{min}$ under nitrogen atmosphere. The detailed morphology, structure and heterojunction feature of the samples were recorded by transmission electron microscopy (TEM) and high resolution TEM (HRTEM) on a JEM-2010 apparatus with an acceleration voltage of $200 \mathrm{kV}$. The surface state and chemical composition of the samples were analyzed by X-ray photoelectron spectroscopy 

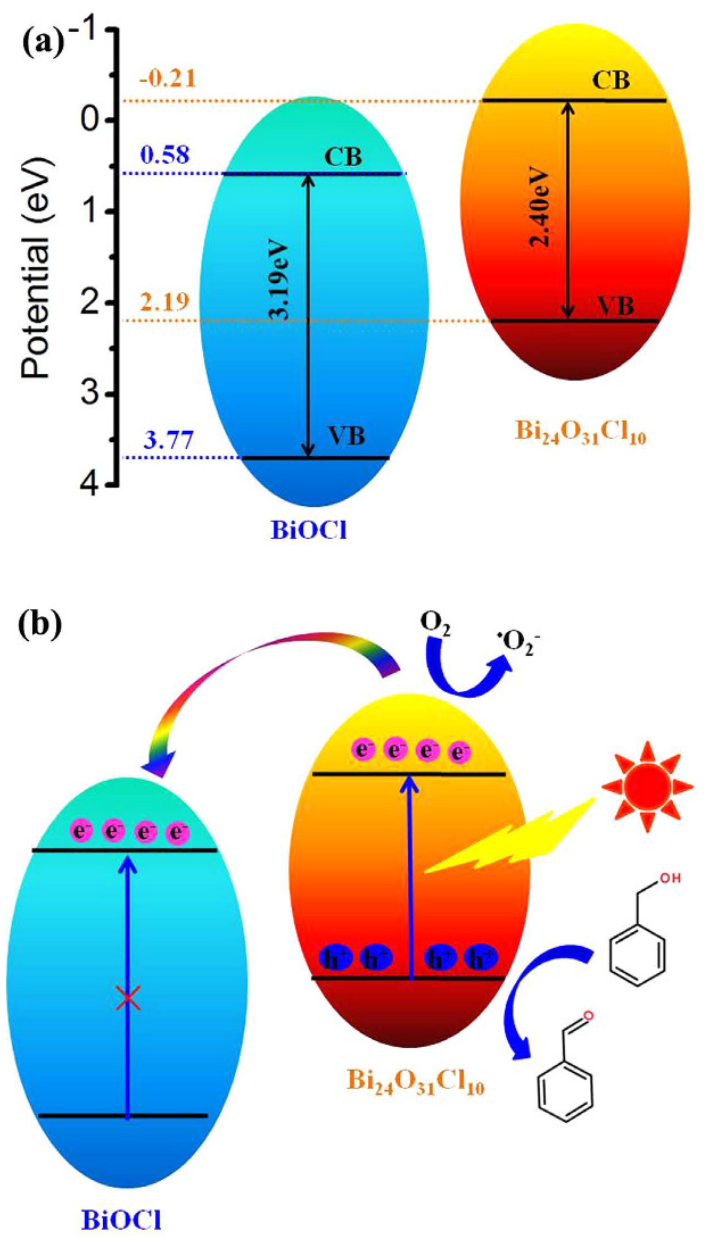

(c)

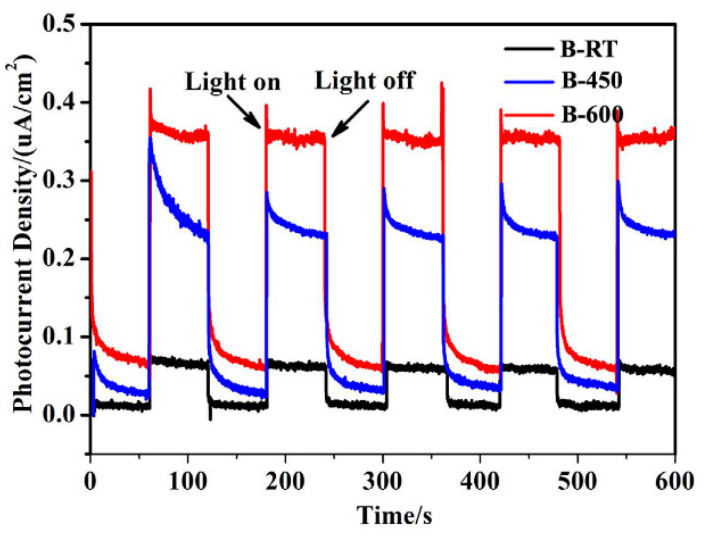

Figure 8. The schematic band diagrams of pure $\mathrm{BiOCl}$ and $\mathrm{Bi}_{24} \mathrm{O}_{31} \mathrm{Cl}_{10}(\mathbf{a})$, the possible charge transfer of photogenerated electron-hole pairs (b) and the transient photocurrent response of samples B-RT, B-450 and B-600.

(XPS), which was carried out on a Thermo Escalab 250Xi with a monochromatic $\mathrm{Al} \mathrm{Ka}(h v=1486.6 \mathrm{eV})$. Raman spectra were recorded on the Horiba Jobin Yvon LabRAM HR800 instrument with the laser excitation of $532 \mathrm{~nm}$. Fouier transform infrared spectroscopy (FT-IR) was performed using a Bruker Tensor 27 spectrophotometer using $\mathrm{KBr}$ powder-pressed pellets. The UV-vis absorption spectra were measured using a UV-vis spectrophotometer (Lambda 750s) in the range of $200 \sim 800 \mathrm{~nm}$. The specific surface area $\left(S_{\mathrm{BET}}\right)$ of the samples was obtained from $\mathrm{N}_{2}$ adsorption-desorption isotherms at $77 \mathrm{~K}$ (ASAP 2020). Prior to the sorption experiment, the materials were dehydrated by evacuation under specific conditions $\left(200^{\circ} \mathrm{C}, 10 \mathrm{~h}\right)$.

The photocurrent transient response measurement was carried out based on a lock-in amplifier. The measurement system is constructed by a sample chamber, a lock-in amplifier (SR 830, Stanford Research Systems, 
Inc.) with a light chopper (SR540, Stanford Research Systems, Inc.) and a source of monochromatic light which is provided by a $500 \mathrm{~W}$ xenon lamp (CHF-XM 500, Trusttech) and a monochromator (Omni- $\lambda 300$, Zolix). The monochromator and the lock-in amplifier were equipped with a computer. The analyzed product is assembled as a sandwich-like structure of ITO-product-ITO, which ITO means an indium tin oxide electrode. All the measurements were performed in air atmosphere and at room temperature.

Electron spin resonance (ESR) spectra were obtained on a Brüker ER200-SRC apparatus. A frequency of about $9.06 \mathrm{GHz}$ was used for a dual-purpose cavity operation. The magnetic field of $0.2 \mathrm{mT}$ was modulated at $100 \mathrm{kHz}$. A microwave power of about $1 \mathrm{~mW}$ was employed. Other parameters for the apparatus were set at: sweep width of $250 \mathrm{mT}$, center field of $250 \mathrm{mT}$, sweep time of $2.0 \mathrm{~min}$, and accumulated 5times. All measurements were performed at room temperature in air without vacuum-pumping. ESR spectra for hydroxyl radicals and superoxide radicals were conducted in methylbenzene solution $(2.0 \mathrm{~mL})$ and methylbenzene solution containing methyl alcohol ( $2 \mathrm{~mL}$, the volume ratio of methyl alcohol being $20 \%$ ), respectively. The experiments were processed in dark and under visible light irradiation with adding $4 \mathrm{mg}$ sample and $0.05 \mathrm{M}$ DMPO.

All calculations were performed with density functional theory (DFT), using the CASTEP program package. The kinetic energy cutoff is $420 \mathrm{eV}$, using the generalized gradient approximation (GGA) with the Perdew-Burke-Ernzerhof (PBE) to treat the models. Geometry optimization is carried out until the residual forces were smaller than $0.01 \mathrm{eV}^{-1}$, and the convergence threshold for self-consistent iteration was set at $5 \times 10^{-7} \mathrm{eV}$.

Photocatalytic activity Test. Selective Oxidation of benzyl alcohol has been widely studied as a model reaction to estimate the photocatalytic performance of catalysts. The photocatalytic activity experiments were carried out in a photochemical reactor fitted with a $500 \mathrm{~W}$ xenon lamp and a visible-light optical filter $(\lambda>420 \mathrm{~nm})$. $10 \mathrm{~mL}$ methylbenzene solution involving alcohol $(1 \mathrm{mM})$ mixed with $0.05 \mathrm{~g}$ sample was magnetically stirred at $25^{\circ} \mathrm{C}$ in water bath. Anaerobic and aerobic reactions were performed by bubbling with pure $\mathrm{N}_{2}$ and $\mathrm{O}_{2}$, respectively, for at least 1 hour before visible-light irradiation. After illuminating 10 hours, the suspension was centrifuged to remove the powder and measured the concentration of the alcohol and product by GC-FID (Shimadzu GC-2014C).

\section{References}

1. Su, Y., Lang, J., Du, C., Bian, F. \& Wang, X. Achieving exceptional photocatalytic activity and selectivity through a well-controlled short-ordered structure: a case study of $\mathrm{Na}_{\mathrm{x}} \mathrm{TaO}_{\mathrm{y}} \cdot \mathrm{nH}_{2} \mathrm{O}$. Chem CatChem 7, 2437-2441 (2015).

2. Mueller, J. A., Goller, C. P. \& Sigman, M. S. Elucidating the significance of $\beta$-hydride elimination and the dynamic role of acid/base chemistry in a palladium-catalyzed aerobic oxidation of alcohols. J. Am. Chem. Soc. 126, 9724-9734 (2004).

3. Mallat, T. \& Baiker, A. Oxidation of alcohols with molecular oxygen on solid catalysts. Chem. Rev. 104, 3037-3058 (2004).

4. Hallett-Tapley, G. L. et al. Plasmon-mediated catalytic oxidation of sec-phenethyl and benzyl alcohols. J. Phys. Chem. C 115, 10784-10790 (2011).

5. Conte, M., Miyamura, H., Kobayashi, S. \& Chechik, V. Spin trapping of Au-H intermediate in the alcohol oxidation by supported and unsupported gold catalysts. J. Am. Chem. Soc. 131, 7189-7196 (2009).

6. Mitsudome, T., Noujima, A., Mizugaki, T., Jitsukawa, K. \& Kaneda, K. Efficient aerobic oxidation of alcohols using a hydrotalcitesupported gold nanoparticle catalyst. Adv. Synth. Catal. 351, 1890-1896 (2009).

7. Xiao, X., Jiang, J. \& Zhang, L. Selective oxidation of benzy alcohol into benzaldehyde over semiconductors under visible light: the case of $\mathrm{Bi}_{12} \mathrm{O}_{17} \mathrm{C}_{12}$ nanobelts. Appl. Catal. B: Environ. 142-143, 487-493 (2013).

8. Hajimohammadi, M., Safari, N., Mofakham, H. \& Deyhimi, F. Highly selective, economical and efficient oxidation of alcohols to alhehydes and ketones by air and sunlight or visible light in the presence of porphyrins sensitizers. Green Chem. 13, 991-997 (2011).

9. Tsukamoto, D. et al. Gold nanoparticles located at the interface of anatase/rutile $\mathrm{TiO}_{2}$ particles as active plasmonic photocatalysts for aerobic oxidation. J. Am. Chem. Soc. 134, 6309-6315 (2012).

10. Furukawa, S., Tamura, A., Shishido, T., Teramura, K. \& Tanaka, T. Solvent-free aerobic alcohol oxidation using $\mathrm{Cu} / \mathrm{Nb}_{2} \mathrm{O}_{5}:$ green and highly selective photocatalytic system. Appl. Catal. B: Environ. 110, 216-220 (2011).

11. Li, C. J., Xu, G. R., Zhang, B. \& Gong, J. R. High selectivity in visible-light-driven partial photocatalytic oxidation of benzyl alcohol into benzldehyde over single-crystalline rutile $\mathrm{TiO}_{2}$ nanorods. Appl. Catal. B: Environ. 115-116, 201-208 (2012).

12. Paszkiewicz, M., Luczak, J., Lisowski, W., Patyk, P. \& Zaleska-Medynska, A. The ILs-assisted solvothermal synthesis of TiO ${ }_{2}$ spheres: the effect of ionic liquids on morphology and photoactivity of $\mathrm{TiO}_{2}$. Appl. Catal. B: Environ. 184, 223-237 (2016).

13. Feng, Y. et al. Improved catalytic capability of mesoporous $\mathrm{TiO}_{2}$ microspheres and photodecomposition of toluene. ACS Appl. Mater. Interfaces 2, 3134-3140 (2010).

14. Guo, C. et al. Directed synthesis of mesoporous $\mathrm{TiO}_{2}$ microspheres: catalysts and their photocatalysis for bisphenol A degradation. Environ. Sci. Technol. 44, 419-425 (2010).

15. Lee, K. et al. Anodic formation of thick anatase $\mathrm{TiO}_{2}$ mesosponge layers for high-efficiency photocatalysis. J. Am. Chem. Soc. 132, 1487-1479 (2010).

16. Wang, J., Yang, G., Lyu, W. \& Yan, W. Thorny $\mathrm{TiO}_{2}$ nanofibers: synthesis, enhanced photocatalytic activity and supercapacitance. J. Alloys Compd. 659, 138-145 (2016).

17. Choudhury, B., Bayan, S., Choudhury, A. \& Chakraborty, P. Narrowing of band gap and effective charge carrier separation in oxygen deficient $\mathrm{TiO}_{2}$ nanotubes with improved visible light photocatalytic activity. J. Colloid Interface Sci. 465, 1-10 (2016).

18. Li, C. J., Xu, G. R., Zhang, B. \& Gong, J. R. High selectivity in visible-light-driven partial photocatalytic oxidation of benzyl alcohol into benzaldehyde over single-crystalline rutile $\mathrm{TiO}_{2}$ nanorods. Appl. Catal. B: Environ. 115-116, 201-208 (2012).

19. Higashimoto, S. et al. Selective photocatalytic oxidation of benzyl alcohol and its derivatives into corresponding aldehydes by molecular oxygen on titanium dioxide under visible light irradiation. J. Catal. 266, 279-258 (2009).

20. Zhang, X., Ai, Z. H., Jia, F. L. \& Zhang, L. Z. Generalized one-pot synthesis, characterization, and photocatalytic activity of hierarchical BiOX $(\mathrm{X}=\mathrm{Cl}, \mathrm{Br}, \mathrm{I})$ nanoplate microspheres. J. Phys. Chem. C 112, 747-753 (2008).

21. Zhang, H., Liu, L. \& Zhou, Z. First-principles studies on facet-dependent photocatalytic properties of bismuth oxyhalides. RSC Adv. 2, 9224-9229 (2012).

22. Gnayem, H. \& Sasson, Y. Hierarchical nanostructured $3 \mathrm{D}$ flowerlike $\mathrm{BiOCl}_{x} \mathrm{Br}_{1-x}$ semiconductors with exceptional visible light photocatalytic activity. ACS Catal. 3, 186-191 (2013).

23. Sun, M., Zhao, Q., Du, C. \& Liu, Z. Enhanced visible light photocatalytic activity in $\mathrm{BiOCl} / \mathrm{SnO}_{2}$ : heterojunction of two wide bandgap semiconductors. RSC Adv. 5, 22740-22752 (2015).

24. Chen, G., Fang, G. L. \& Tang, G. D. Photoluminescence and photocatalytic properties of $\mathrm{BiOCl}_{\text {and }} \mathrm{Bi}_{24} \mathrm{O}_{31} \mathrm{Cl}_{10}$ nanostructures synthesized by electrolytic corrosion of metal Bi. Mater. Res. Bull. 48, 1256-1261 (2013). 
25. Li, Q., Xian, Z. \& Jun, Y. Exploring the effects of nanocrystal facet orientations in $\mathrm{g}^{-} \mathrm{C}_{3} \mathrm{~N}_{4} / \mathrm{BiOCl}$ heterostructures on photocatalytic performance. Nanoscale 7, 18971-18983 (2015).

26. Jiang, S. et al. In situ synthesis of hierarchical flower-like $\mathrm{Bi}_{2} \mathrm{~S}_{3} / \mathrm{BiOCl}$ composite with enhanced visible light photocatalytic activity. Appl. Surf. Sci. 290, 313-319 (2014).

27. Dong, F., Sun, Y., Fu, M. Z., Wu, S. \& Lee, C. Room temperature synthesis and highly enhanced visible light photocatalytic activity of porous $\mathrm{BiOI} / \mathrm{BiOCl}$ composites nanoplates microflowers. J. Hazard. Mater. 219-220, 26-34 (2012).

28. Liu, B. et al. Efficient visible light photocatalytic activity of CdS on (001) facets exposed to BiOCl. New J. Chem. 38, 2273-2277 (2014).

29. Shamaila, S., Sajjad, A. K. L., Chen, F. \& Zhang, J. $\mathrm{WO}_{3} / \mathrm{BiOCl}$, a novel heterojunction as visible light photocatalyst. J. Colloid Interface Sci. 356, 465-472 (2011).

30. He, Z. et al. $\mathrm{BiOCl} / \mathrm{BiVO}_{4} \mathrm{p}-\mathrm{n}$ heterojunction with enhanced photocatalytic activity under visible-light irradiation. J. Phys. Chem. C 118, 389-398 (2014).

31. Chang, X. et al. Enhancement of photocatalytic activity over $\mathrm{NaBiO}_{3} / \mathrm{BiOCl}$ composite prepared by an in situ formation strategy. Catal. Today 153, 193-199 (2010).

32. Li, L. P., Su, Y. G. \& Li, G. S. Size-induced symmetric enhancement and its relevance to photoluminescence of scheelite $\mathrm{CaWO}_{4}$ nanocrystals. AppL. Phys. Lett. 90, 054105-3 (2007).

33. Jin, X. et al. Bismuth-rich strategy induced photocatalytic molecular oxygen activation properties of bismuth oxyhalogen: the case of $\mathrm{Bi}_{24} \mathrm{O}_{31} \mathrm{Cl}_{10}$. Appl. Catal. B: Environ. 165, 668-675 (2015).

34. Wei, W., Dai, Y. \& Huang, B. First principle characterization of Bi-based photocatalysts: $\mathrm{Bi}_{12} \mathrm{TiO}_{20}, \mathrm{Bi}_{2} \mathrm{Ti}_{2} \mathrm{O}_{7}$ and $\mathrm{Bi}_{4} \mathrm{Ti}_{3} \mathrm{O}_{12}$. J. Phys. Chem. C 113, 5658-5663 (2009).

35. Li, J., Zhang, L. Z., Li, Y. J. \& Yu, Y. Synthesis and internal electric field dependent photoreactivity of $\mathrm{Bi}_{3} \mathrm{O}_{4} \mathrm{Cl}$ single-crystalline nanosheets with high $\{001\}$ facet exposure percentages. Nanoscale 6, 167-171 (2014).

36. Myung, Y. et al. Highly conducting, n-type $\mathrm{Bi}_{12} \mathrm{O}_{16} \mathrm{Cl}_{6}$ nanosheets with superlattice-like structure. Chem. Mater. 27, 7710-7718 (2015).

37. Lv, C. et al. Realizing nanosized interfacial contact via constructing $\mathrm{BiVO}_{4} / \mathrm{Bi}_{4} \mathrm{O}_{2} \mathrm{O}_{11}$ element-copied heterojunction nanofibers for superior photocatalytic properties. Appl. Catal. B: Environ. 179, 54-60 (2015).

38. Eggenweiler, U., Keller, E. \& Krämer, V. Redetermination of the crystal structure of the 'Arppe compound' $\mathrm{Bi}_{24} \mathrm{O}_{31} \mathrm{Cl}_{10}$ and the isomorphous $\mathrm{Bi}_{24} \mathrm{O}_{31} \mathrm{Br}_{10}$. Acta Crystallographica Section B B56, 431-437 (2000).

39. Wang, L. et al. A dye-sensitized visible light photocatalyst- $\mathrm{Bi}_{24} \mathrm{O}_{31} \mathrm{Cl}_{10}$. Sci. Rep. 4, 1-8 (2014).

40. Li, F. T. et al. In-situ one-step synthesis of novel $\mathrm{BiOCl} / \mathrm{Bi}_{24} \mathrm{O}_{31} \mathrm{Cl}_{10}$ heterojuncitons via self-combustion of ionic liquid with enchanced visible-light photocatalytic activities. Appl. Catal. B: Environ. 150-151, 574-584 (2014).

41. Cheng, G., Xiong, J. \& Stadler, F. J. Facile template-free and fast refluxing synthesis of 3D desertrose-like BiOCl nanoarchitectures with superior photocatalytic activity. New. J. Chem. 37, 3207-3213 (2013).

42. Yu, J., Xiang, Q. \& Zhou, M. Preparation, characterization and visible-light-driven photocatalytic activity of Fe-doped titania nanorods and first-principles study for electronic structures. Appl. Catal. B: Environ. 90, 595-602 (2009).

43. Moulder, J. F., Stickle, W. F., Sobol, P. E. \& Bomben, K. D. Handbook of X-ray photoelectron spectroscopy physical electronics division, Perkin-Elmer Corporation, Eden Prairie, MN, USA, (1992).

44. He, Y. et al. Z-scheme $\mathrm{SnO}_{2-\mathrm{x}} / \mathrm{g}-\mathrm{C}_{3} \mathrm{~N}_{4}$ composite as an efficient photocatalyst for dye degradation and photocatalytic $\mathrm{CO}_{2}$ reduction. Sol. Energy Mater. Sol. C. 137, 175-184 (2015)

45. Liu, G. \& Jaegermann, W. XPS and UPS characterization of the $\mathrm{TiO}_{2} / \mathrm{ZnPcGly}$ heterointerface: alignment of energy levels. J. Phys. Chem. B 106, 5814-5819 (2002).

46. $\mathrm{Li}, \mathrm{X}$. H. et al. Local chemical states and thermal stabilities of nitrogen dopants in $\mathrm{ZnO}$ film studied by temperature-dependent $\mathrm{X}$-ray photoelectron spectroscopy. Appl. Phys. Lett. 95, 191903-191903-3 (2009).

47. Fan, W. Q. et al. Fabrication of $\mathrm{TiO}_{2}-\mathrm{BiOCl}$ double-layer nanostructure arrays for photoelectrochemical water splitting. CrystEngComm 16, 820-825 (2014).

48. Weng, S., Chen, B., Xie, L., Zheng, Z. \& Liu, P. Facile in situ synthesis of Bi/BiOCl nanocomposite with high photocatalytic activity. J. Mater. Chem. A 1, 3068-3075 (2013).

49. Xu, Y., Xu, S., Wang, S., Zhang, Y. \& Li, G. Citric acid modulated electrochemical synthesis and photocatalytic behavior of BiOCl nanoplates with exposed $\{001\}$ facets. Dalton Trans. 43, 479-485 (2014).

50. Schwartz, G. P. et al. Core-level photoemission measurements of valence-band offsets in highly strained heterojunctions: Si-Ge system. Phys. Rev. B 39, 1235-1241 (1989).

51. Xie, T., Xu, L., Liu, C., Yang, J. \& Wang, M. Magnetic composite BiOCl-SrFe ${ }_{12} \mathrm{O}_{19}$ : a novel p-n type heterojunction with enhanced photocatalytic activity. Dalton Trans. 43, 2211-2220 (2014).

52. Cheng, G., Xiong, J. \& Stadler, F. J. Facile template-free and fast refluxing synthesis of 3D desertrose-like nanoarchitectures with superior photocatalytic activity. New J. Chem. 37, 3207-3213 (2013).

53. Fruth, V., Popa, M., Berger, D., Ionica, C. M. \& Jitianu, M. Phase investigation in the antimony doped $\mathrm{Bi}_{2} \mathrm{O}_{3}$ system. J. Eur. Ceram. Soc. 24, 1295-1299 (2004)

54. Song, J., Mao, C., Niu, H., Shen, Y. \& Zhang, S. Hierarchical structured bismuth oxychlorides: self-assembly from nanoplates to nanoflowers via a solvothermal route and their photocatalytic properties. CrystEngComm 12, 3875-3881 (2010).

55. Yang, W., Wen, Y., Chen, R., Zeng, D. \& Shan, B. Study of structural , electronic and optical properties of tungsten doped bismuth oxychloride by DFT calculations. Phys. Chem. Chem. Phys. 16, 21349-21355 (2014).

56. Zhu, L. P. et al. Self-assembled 3D BiOCl hierarchitectures: tunable synthesis and characterization, CrystEngComm 12, 3791-3796 (2010).

57. Wang, D. H. et al. Nanosheet-constructed porous BiOCl with Dominant $\{001\}$ Facets for Superior Photosensitized Degradation. Nanoscale 4, 7780-7785 (2012).

58. Zhang, Y. $\mathrm{H} . \& \mathrm{Xu}, \mathrm{Y} . \mathrm{J} . \mathrm{Bi}_{2} \mathrm{WO}_{6}$ : a highly chemoselective visible light photocatalyst toward aerobic oxidation of benzylic alcohols in water. RSC Adv. 4, 2904-2910 (2014).

59. Guan, M. et al. Vacancy associates promoting solar-driven photocatalytic activity of ultrathin bismuth oxychoride nanosheets. J. Am. Chem. Soc. 135, 10411-10417 (2013).

60. Sun, M. et al. Efficient degradation of azo dyes over $\mathrm{Sb}_{2} \mathrm{~S}_{3} / \mathrm{TiO}_{2}$ heterojunction under visible light irradiation. Ind. Eng. Chem. Res. 51, 2897-2903 (2012).

61. He, W. et al. Production of reactive oxygen species and electrons from photoexcited $\mathrm{ZnO}$ and $\mathrm{ZnS}$ nanoparticles: a comparative study for unraveling their distinct photocatalytic activies. J. Phys. Chem. C 120, 3187-3195 (2016).

\section{Acknowledgements}

This work was supported by the National Natural Science Foundation of China (NSFC NO. 51462025) and the Inner Mongolia Provincial Natural Science Foundation of China (NO. 2013MS0204). 


\section{Author Contributions}

C.D. conceived the project, analyzed the data and wrote the final paper. X.L. synthesized and characterized the samples. Y.S. characterized the samples and analyzed the data. Q.Z. designed the experiments. Z.L. and C.D. discussed the results and commented on the manuscript.

\section{Additional Information}

Supplementary information accompanies this paper at http://www.nature.com/srep

Competing financial interests: The authors declare no competing financial interests.

How to cite this article: $\mathrm{Liu}$, X. et al. Constructing $\mathrm{Bi}_{24} \mathrm{O}_{31} \mathrm{Cl}_{10} / \mathrm{BiOCl}$ heterojunction via a simple thermal annealing route for achieving enhanced photocatalytic activity and selectivity. Sci. Rep. 6, 28689; doi: 10.1038/srep28689 (2016).

(c) (i) This work is licensed under a Creative Commons Attribution 4.0 International License. The images or other third party material in this article are included in the article's Creative Commons license, unless indicated otherwise in the credit line; if the material is not included under the Creative Commons license, users will need to obtain permission from the license holder to reproduce the material. To view a copy of this license, visit http://creativecommons.org/licenses/by/4.0/ 